\title{
Renal unit practitioners' knowledge, attitudes and practice regarding the safety of unfractionated heparin for chronic haemodialysis
}

\begin{tabular}{|c|c|}
\hline \multicolumn{2}{|c|}{$\begin{array}{l}\text { Authors: } \\
\text { Debra Ockhuis }{ }^{1} \\
\text { Una Kyriacos }^{1}\end{array}$} \\
\hline \multicolumn{2}{|c|}{$\begin{array}{l}\text { Affiliations: } \\
\text { 'Faculty of Health Sciences, } \\
\text { Department of Health and } \\
\text { Rehabilitation Sciences, } \\
\text { University of Cape Town, } \\
\text { South Africa }\end{array}$} \\
\hline \multicolumn{2}{|c|}{$\begin{array}{l}\text { Correspondence to: } \\
\text { Debra Ockhuis }\end{array}$} \\
\hline \multicolumn{2}{|c|}{$\begin{array}{l}\text { Email: } \\
\text { d.ockhuis@uct.ac.za }\end{array}$} \\
\hline \multicolumn{2}{|c|}{$\begin{array}{l}\text { Postal address: } \\
\text { Anzio Road, Observatory } \\
\text { 7925, South Africa }\end{array}$} \\
\hline \multicolumn{2}{|c|}{$\begin{array}{l}\text { Dates: } \\
\text { Received: } 21 \text { Aug. } 2014 \\
\text { Accepted: } 18 \text { May } 2015 \\
\text { Published: } 16 \text { Sept. } 2015\end{array}$} \\
\hline \multicolumn{2}{|c|}{$\begin{array}{l}\text { How to cite this article: } \\
\text { Ockhuis, D. \& Kyriacos, } \\
\text { U., 2015, 'Renal unit } \\
\text { practitioners' knowledge, } \\
\text { attitudes and practice } \\
\text { regarding the safety of } \\
\text { unfractionated heparin } \\
\text { for chronic haemodialysis', } \\
\text { Curationis } 38(1) \text {, Art. \#1447, } \\
12 \text { pages. http://dx.doi. } \\
\text { org/10.4102/curationis. } \\
\text { v38i1.1447 }\end{array}$} \\
\hline \multicolumn{2}{|c|}{$\begin{array}{l}\text { Copyright: } \\
\text { (C) 2015. The Authors. } \\
\text { Licensee: AOSIS } \\
\text { OpenJournals. This work is } \\
\text { licensed under the Creative } \\
\text { Commons Attribution } \\
\text { License. }\end{array}$} \\
\hline \multicolumn{2}{|l|}{ Read online: } \\
\hline 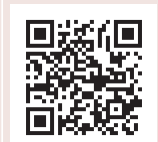 & $\begin{array}{l}\text { Scan this QR } \\
\text { code with your } \\
\text { smart phone or } \\
\text { mobile device } \\
\text { to read online. }\end{array}$ \\
\hline
\end{tabular}

Background: Chronic haemodialysis for adult patients with end-stage kidney failure requires a patent extracorporeal circuit, maintained by anticoagulants such as unfractionated heparin (UFH). Incorrect administration of UFH has safety implications for patients.

Objectives: Firstly, to describe renal practitioners' self-reported knowledge, attitudes and practice (KAP) regarding the safe use of UFH and its effects; secondly, to determine an association between KAP and selected independent variables.

Method: A cross-sectional descriptive survey by self-administered questionnaire and nonprobability convenience sampling was conducted in two tertiary hospital dialysis units and five private dialysis units in 2013.

Results: The mean age of $74 / 77$ respondents (96.1\%), was 41.1 years. Most $(41 / 77,53.2 \%)$ had $0-5$ years of renal experience. The odds of enrolled nurses having poorer knowledge of UFH than registered nurses were 18.7 times higher at a 95\% Confidence Interval (CI) (1.9-187.4) and statistically significant $(P=0.013)$. The odds of delivering poor practice having $\leq$ five years of experience and no in-service education were 4.6 times higher at a 95\% CI (1.4-15.6), than for respondents who had $\geq$ six years of experience $(P=0.014)$ and 4.3 times higher $(95 \%$ CI 1.1-16.5) than for respondents who received in-service education $(P=0.032)$, the difference reaching statistical significance in both cases.

Conclusion: Results suggest that the category of the professional influences knowledge and, thus, safe use of UFH, and that there is a direct relationship between years of experience and quality of haemodialysis practice and between having in-service education and quality of practice.

\section{Introduction}

\section{Problem statement}

Patients with end-stage kidney failure (ESKF) depend on safe chronic haemodialysis therapy to restore homeostasis. Safe haemodialysis treatment includes correct dosages of unfractionated heparin (UFH), currently the most widely used anticoagulant for this purpose. Failure to adhere to correct dosages of UFH exposes patients to the risk of blood clotting in the extracorporeal circuit or prolonged time for arterio-venous fistulae cannulated sites to stop bleeding (Davenport 2009) at the conclusion of the session. Renal unit practitioners need specialised knowledge and skill pertaining to the use of UFH in haemodialysis. Surprisingly, there is a dearth of available current literature on renal unit practitioners' knowledge and practice regarding the safe administration of UFH, and even less available literature on practitioners' attitudes concerning safe administration of UFH.

\section{Aims of the study}

The primary purpose of the study was to describe renal unit practitioners' knowledge, attitudes and practice (KAP) regarding the safe use and effects of UFH in selected adult, chronic haemodialysis centres in the Cape Town Metropole, South Africa. The secondary purpose was to determine whether there was an association between selected independent variables (category of renal unit practitioner, years of experience, duration of orientation period and in-service education in pharmacological actions of UFH) and practitioners' KAP concerning the safe use and effects of UFH. The null hypotheses stated that the independent variables did not influence practitioners' KAP regarding safe use and effects of UFH.

\section{Background}

UFH has been used since the inception of chronic haemodialysis therapy in the 1930s. For patients on chronic haemodialysis, a nephrologist prescribes treatment for about 3-4 hours two or three 
times a week. During the haemodialysis, 200-250 mL/minute of the patient's blood volume is extracorporeal and can clot, but to reduce the risk of clotting (Roy \& Kalra 2012:107) an anticoagulant such as UFH is administered. In local renal settings the South African Renal Society guidelines (2006) and other international guidelines are provided on the use and dosage of UFH.

Although 184 related published studies between 2000 and 2014 were located in three databases, no KAP studies related to renal practitioners' use of UFH appear to have been published. One systematic review by the Cochrane Renal Group (Palmer et al. 2014) was located but was unrelated to the present study. Renal unit practitioners are reported to be confused, concerned and even outspoken about safety aspects of UFH when preparing, administering and monitoring its effects (Pittard 2001:75; Baglin et al. 2006:21; Brunet et al. 2008:794). Suranyi and Chow (2010:386) have appealed to nurses to regularly review and update their knowledge regarding UFH.

\section{Trends}

UFH prevents clotting in the extracorporeal haemodialysis circuit, but decades after its first use warnings continue of it being a high-alert medication (Institute for Safe Medication Practices [ISMP] 2006a) If safety precautions such as ensuring the right dose of UFH at the right time of administration and close monitoring are absent during haemodialysis therapy, serious adverse consequences such as anaphylaxis, heparin-induced thrombocytopenia and vascular access bleeding can result (Pittard 2001:75; Furushahi et al. 2002:1457; Bircher et al. 2006:1437). In the United Kingdom (UK), the National Patient Safety Agency (NPSA 2006) reported that anticoagulants are often the cause of preventable harm to patients, which can result in admission to hospital and even death. The Joint Commission on Accreditation of Healthcare Organisations (JCAHO) in the United States of America (USA) developed a project supporting the adoption of safety measures for anticoagulants as a National Patient Safety Goal, implemented in January 2009 (JCAHO 2009).

Approximately 35\% of UFH is filtered by normal kidneys, but for patients on chronic haemodialysis, excess heparin cannot be excreted as it cannot be dialysed (Pittard 2001:75). Most protocols for use of UFH in the participating Cape Town Metropole dialysis centres prescribe a standard dose of 5000 IU of heparin three times a week for patients during haemodialysis sessions. This means that a patient's yearly dose of UFH amounts to approximately 780000 $\mathrm{IU}$, thus, predisposing the patient to long-term effects of UFH, such as osteoporosis (Pittard 2001:75; Furuhashi et al. 2002:1457). Although anticoagulants are widely used, errors and lack of tight control of the treatment of patients receiving anticoagulants continue (Institute for Healthcare Improvement [IHI] 2008) and heparin 'is frequently unmonitored, untested and unsupervised in many dialysis facilities' (Pittard 2001:75).
The NPSA reported 480 cases of patient harm from the use of anticoagulation therapy in the UK between 1990 and 2002 (NPSA 2006), of which 28 deaths were associated with the use of UFH but not linked to deaths of patients on chronic haemodialysis. Errors related to UFH accounted for $2.1 \%$ of total records submitted to the USA MedMarx national error database, of which $4.5 \%-5.5 \%$ were harmful (Niccolai et al. 2004:146S). In a USA study (Grissinger et al. 2010:195), patient harm from UFH accounted for $1.4 \%$ to $4.9 \%$ of the reports submitted, occurring mostly (56\%) during administration. Policy guidelines on monitoring baseline clotting studies before the administration of the initial and subsequent doses of UFH were available in only one of the seven Cape Town dialysis centres included in the study. In the other six centres, nephrologists prescribed individual patient dosages of UFH on medication charts. Five of the seven dialysis centres had a protocol on how to administer UFH. No data on adverse events (AEs) or deaths of adult patients on chronic haemodialysis related to UFH were available from the Cape Town Metropole. Moreover, there is no published data on morbidity and mortality associated with anticoagulation therapy within the South African renal population.

The results of this local study fill a gap in existing published data on renal practitioners' KAP concerning the safe use of UFH, which may contribute to some extent to evidence-based renal nursing practice in South Africa to advance quality care and patient safety.

\section{Definition of key concepts}

Adverse event: a negative situation arising from medical care that results in patient injury from unsafe care rendered, whether intentional or unintentional (World Health Organisation 2005).

Anticoagulant: an agent that stops blood from clotting (Dorland 2007:103).

Chronic kidney disease / end-stage kidney failure (synonym): failed natural kidney functioning. Kidneys are unable to filter toxins and maintain fluid balance.

Chronic haemodialysis centre / unit: treatment centre where patients with ESKF receive chronic haemodialysis therapy.

Clinical technologist: has a 3-year diploma or 4-year bachelor's degree in nephrology clinical technology, who is registered with the Health Professions Council of South Africa and who is permitted to perform acute and chronic adult haemodialysis, paediatric haemodialysis and peritoneal dialysis, and also monitor haemodialysis water treatment plants, and procedures in nephrology, including patients' vital signs monitoring, intravenous cannulation and administration, administering blood transfusions, and administering drugs and managing their side-effects (South African Qualifications Authority 2014). 


\begin{tabular}{|c|c|c|c|c|c|c|c|}
\hline \multirow[t]{3}{*}{ Information categories } & \multicolumn{7}{|c|}{ Dialysis institutions/ Administration body } \\
\hline & \multicolumn{2}{|c|}{ Public } & \multicolumn{5}{|c|}{ Private } \\
\hline & Centre 1 & Centre 2 & Centre 3 & Centre 4 & Centre 5 & Centre 6 & Centre 7 \\
\hline Number of dialysis units & 1 & 1 & 1 & 1 & 1 & 1 & 1 \\
\hline Classification & Tertiary & Tertiary & $\mathrm{n} / \mathrm{a}$ & $\mathrm{n} / \mathrm{a}$ & $\mathrm{n} / \mathrm{a}$ & $\mathrm{n} / \mathrm{a}$ & $\mathrm{n} / \mathrm{a}$ \\
\hline Registered nurses $n(\%)$ & $8(38.1 \%)$ & $1758.6)$ & $8(66.7)$ & $10(76.9)$ & $14(73.7)$ & $4(100)$ & $5(83.3)$ \\
\hline Enrolled nurses $n(\%)$ & $5(23.8 \%)$ & $5(17.2)$ & $1(8.3)$ & $1(7.7)$ & $2(10.5)$ & - & $1(16.7)$ \\
\hline Clinical technologists $n(\%)$ & $8(38.1)$ & $7(24.1)$ & $3(25)$ & $2(15.4)$ & $3(15.8)$ & - & - \\
\hline Total number of permanent renal unit practitioners $(N=104)$ & 21 & 29 & 12 & 13 & 19 & 4 & 6 \\
\hline
\end{tabular}

Number of dialysis units included in study: $n=7$.

n/a, not applicable.

Enrolled (staff) nurse: practises basic nursing in the manner and to the level prescribed under the supervision of a professional nurse (South African Nursing Council, Republic of South Africa 2005:ch2).

Registered (professional) nurse: is qualified and competent to independently practise comprehensive nursing in the manner and to the level prescribed, and who is capable of assuming responsibility and accountability for such practice (South African Nursing Council, Republic of South Africa 2005:ch2).

Renal unit practitioner: registered nurses (RNs), enrolled nurses (ENs) and clinical technologists (CTs) working in a haemodialysis centre.

Unfractionated heparin / heparin: a 'commercially' prepared drug (Niccolai et al. 2004:146S) that indirectly inhibits the clotting cascade of events and prevents the formation of blood clots (Fischer 2007:181).

\section{Contribution to field}

The study addresses gaps in the published literature concerning UFH prescription practices, dosage, administration and monitoring of its effects (Ouseph \& Ward 2000:181; Pittard 2001:75; Baglin et al. 2006:21; Brunet et al. 2008:794).

\section{Ethical considerations}

Principles of the Helsinki Declaration (World Medical Association 2008) were upheld. After ethics approval (FHS HREC Ref.642/2012) of the protocol by the University of Cape Town (UCT) Faculty of Health Sciences' Human Research Ethics Committee, institutional gatekeepers gave permission to gain entry to the research sites. The informed consent form assured potential research respondents that participation was voluntary, withdrawal from the study at any time would incur no penalties, encryption ensured their anonymity and information they provided was confidential.

There were no anticipated hazards and none were reported. A potential benefit of this study is to provide data from a South African perspective. These data may be useful for improved service delivery and in-service training programmes to promote patient safety.

\section{Research method and design Design}

A descriptive cross-sectional design was employed for a KAP survey amongst renal unit practitioners (RNs, ENs and CTs) between March and April 2013.

\section{Setting}

Seven adult dialysis centres (Table 1), from two tertiary government hospitals and five dialysis centres from a private dialysis provider, were invited to participate.

\section{Sampling}

A purposive sampling method was employed. To estimate a sample size in the absence of published data, the prevalence of a satisfactory level of knowledge of the safe use and effects of UFH amongst respondents was used and set at $50 \%(n=52)$ of the population $(N=104)$, guided by personal clinical experience. Using StatCalc (EpiInfo Version 7), a sample size of 82 was determined. Although attitudes and practice scores were also investigated, these variables were not used to estimate a sample size.

\section{Instrumentation}

A self-administered questionnaire was constructed, guided by the study aims and objectives, personal experience and available published literature, to ensure content validity. The development stage of determining content validity incorporated three steps:

- domain identification (knowledge, attitudes and practice)

- item generation

- instrument formation (development of the survey questionnaire and deciding on a suitable sequence of the items) (Schilling et al. 2007:362).

The structured part of the questionnaire consisted of fixed, closed questions with pre-coded response choices for ease of counting answers for quantitative data and analysis (Bowling \& Ebrahim 2007:405). Open-ended questions (Appendix 1 Table 1 - A1) minimised successful guessing to determine respondents' actual KAP regarding UFH, but data are not presented in this article. 
TABLE 2: Demographics of respondents.

\begin{tabular}{|c|c|c|c|}
\hline \multirow[t]{3}{*}{ Variables } & \multicolumn{3}{|c|}{ Professional Category } \\
\hline & $\mathrm{RN}-n=51$ & CT $-n=21$ & $\mathrm{EN}-\boldsymbol{n}=\mathbf{5}$ \\
\hline & $n(\%)$ & $n(\%)$ & $n(\%)$ \\
\hline \multicolumn{4}{|l|}{ Age $(n=74 *)$} \\
\hline $21-30$ & $5(9.8)$ & $10(47.6)$ & $0(0.0)$ \\
\hline $31-40$ & $10(19.6)$ & $8(38.1)$ & $1(20.0)$ \\
\hline $41-50$ & $19(37.3)$ & $2(9.5)$ & $4(80.0)$ \\
\hline $51-60$ & $12(23.5)$ & $1(4.8)$ & $0(0.0)$ \\
\hline$>61$ & $2(3.9)$ & $0(0.0)$ & $0(0.0)$ \\
\hline Missing & $3(5.9)$ & $0(0.0)$ & $0(0.0)$ \\
\hline Subtotal & $48(94.1)$ & $21(100.0)$ & $5(100.0)$ \\
\hline Total & $51(100.0)$ & $21(100.0)$ & $5(100.0)$ \\
\hline \multicolumn{4}{|l|}{ Gender ( $n=77)$} \\
\hline Male & $6(11.8)$ & $13(61.9)$ & $0(0.0)$ \\
\hline Female & $45(88.2)$ & $8(38.1)$ & $5(100.0)$ \\
\hline Total & $51(100.0)$ & $21(100.0)$ & $5(100)$ \\
\hline \multicolumn{4}{|l|}{ Citizen $(n=76 *)$} \\
\hline South Africa & $48(94.1)$ & $20(95.2)$ & $5(100.0)$ \\
\hline Other & $2(3.9)$ & $1(4.8)$ & $0(0.0)$ \\
\hline Missing & $1(2.0)$ & $0(0.0)$ & $0(0.0)$ \\
\hline Subtotal & $50(98.0)$ & $21(100.0)$ & $5(100.0)$ \\
\hline Total & $51(100.0)$ & $21(100.0)$ & $5(100.0)$ \\
\hline \multicolumn{4}{|l|}{ Qualification ( $n=77)$} \\
\hline PGDNN & $7(13.7)$ & $0(0.0)$ & $0(0.0)$ \\
\hline Dip CC & $8(15.7)$ & $0(0.0)$ & $0(0.0)$ \\
\hline Dip Nephro CT & $0(0.0)$ & $11(52.4)$ & $0(0.0)$ \\
\hline B Tech Nephro CT & $0(0.0)$ & $8(38.1)$ & $0(0.0)$ \\
\hline OJT & $27(52.9)$ & $0(0.0)$ & $5(100.0)$ \\
\hline PGDNN+Dip CC & $2(3.9)$ & $0(0.0)$ & $0(0.0)$ \\
\hline Dip CC+OJT & $6(11.8)$ & $0(0.0)$ & $0(0.0)$ \\
\hline $\begin{array}{l}\text { Dip Nephro CT + B } \\
\text { Tech Nephro CT }\end{array}$ & $0(0.0)$ & $1(4.8)$ & $0(0.0)$ \\
\hline Dip Nephro CT + OJT & $0(0.0)$ & $1(4.8)$ & $0(0.0)$ \\
\hline PGDNN+Dip CC + OJT & $1(2.0)$ & $0(0.0)$ & $0(0.0)$ \\
\hline Total & $51(100.0)$ & $21(100.0)$ & $5(100.0)$ \\
\hline \multicolumn{4}{|c|}{ Experience in years $(n=77)$} \\
\hline $0-5$ & $29(56.9)$ & $10(47.6)$ & $2(40.0)$ \\
\hline $6-40$ & $22(43.1)$ & $11(52.4)$ & $3(60.0)$ \\
\hline Total & $51(100.0)$ & $21(100.0)$ & $5(100.0)$ \\
\hline \multicolumn{4}{|c|}{ Orientation by mentor $(n=76 *)$} \\
\hline Yes & $35(68.6)$ & $17(81.0)$ & $2(40.0)$ \\
\hline No & $16(31.4)$ & $4(19.0)$ & $2(40.0)$ \\
\hline Missing & $0(0.0)$ & $0(0.0)$ & $1(20.0)$ \\
\hline Subtotal & $51(100.0)$ & $21(100.0)$ & $4(80.0)$ \\
\hline Total & $51(100.0)$ & $21(100.0)$ & $5(100.0)$ \\
\hline \multicolumn{4}{|c|}{ Duration of orientation $(n=77)$} \\
\hline On orientation & $1(2.0)$ & $0(0.0)$ & $0(0.0)$ \\
\hline Days & $0(0.0)$ & $1(4.8)$ & $0(0.0)$ \\
\hline Weeks & $14(27.5)$ & $6(28.6)$ & $5(100.0)$ \\
\hline Months & $22(43.1)$ & $8(38.1)$ & $0(0.0)$ \\
\hline Not Applicable & $14(27.5)$ & $6(28.6)$ & $0(0.0)$ \\
\hline Total & $51(100.1)$ & $21(100.1)$ & $5(100.0)$ \\
\hline \multicolumn{4}{|c|}{ Inservice of UFH ( $\left.n=76^{*}\right)$} \\
\hline Yes & $13(25.5)$ & $11(52.4)$ & $5(100.0)$ \\
\hline No & $37(72.5)$ & $10(47.6)$ & $0(0.0)$ \\
\hline Missing & $1(2.0)$ & $0(0.0)$ & $0(0.0)$ \\
\hline Subtotal & $50(98.0)$ & $21(100.0)$ & $5(100.0)$ \\
\hline Total & $51(100.0)$ & $21(100.0)$ & $5(100.00$ \\
\hline
\end{tabular}

*, denotes missing data.

BTech Nephro CT, bachelor in technology (nephrology); CT=clinical technologist; Dip CC BTech Nephro CT, bachelor in technology (nephrology); $\mathrm{CT}=$ clinical technologist; $\mathrm{Dip}$ CC,
diploma in critical care; Dip Nephro CT, diploma in clinical technology nephrology); EN diploma in critical care; Dip Nephro CT, diploma in clinical technology nephrology); EN,
enrolled nurse; OJT, on job training; PGDNN, postgraduate diploma in nephrology nursing; $\mathrm{RN}$, registered nurse; UFH, unfractionated heparin.

\section{Validity}

Face and content validity of the questionnaire were determined by three experts using the Index of Content Validity (CVI) approach (Schilling et al. 2007). Overall, the experts' evaluation of the importance of each question was positive, as most responses $(44 / 45,97.8 \%)$ fell in the 'extremely relevant' (4/4) category.

\section{Reliability}

The questionnaire was then pilot tested for test-retest reliability by three different respondents, representing the same composition as those in the actual study but not participating in the main study, after an interval of one week (Marx et al. 2003:730). Test-retest data were unchanged for the RN, but for both the EN and CT, the second attempt was worse than the first. A Pearson product-moment correlation (which does not penalise systematic error) showed that for the $\mathrm{RN}$ there was a strong, positive correlation between test 1 and test 2 results, which was statistically significant $(r=1, n=3$, $P=<0.001)$. For the EN and CT there was also a strong positive correlation between test results, but this was not statistically significant. For the RN, systematic error could be attributed to a learning effect (Rousson, Gasser \& Seifert 2002). For the EN and CT, a worse test-retest result could be attributed to a fatigue effect, which shows that the systematic error should be treated differently, according to the situation (Rousson et al. 2002). Neither learning effect nor fatigue effect are directly related to reliability.

\section{Data collection procedure}

Unit managers agreed to recruit respondents who met inclusion criteria, obtained written consent, and distributed and collected completed, self-administered questionnaires within two weeks.

\section{Data protection and data analysis}

Data from 36 (of 45) closed-ended questions were captured on password-protected pre-coded Microsoft $₫$ Office Excel ${ }^{\circledR}$ 2007 spreadsheets. Missing data were labelled '1001' for descriptive and frequency statistics, but removed for inferential statistics and changed to a blank space to reduce skewed interpretations.

For quality assurance of data entry, a Masters-prepared professional nurse entered data from a random selection of 8 of 77 completed questionnaires (10.4\%) onto a Microsoft ${ }^{\circledR}$ Office Excel ${ }^{\circledR} 2007$ spreadsheet. There was a $93.3 \%(42 / 45)$ agreement and 6.7\% (3/45) disagreement between recordings so accepted, and this was not too far off the predetermined level of acceptance set at $95 \%$. Incorrect entries on the spreadsheets were corrected for two respondents.

Descriptive statistical analysis was performed for frequency distributions and measurement of central tendency (for 


\begin{tabular}{|c|c|c|c|c|c|}
\hline KAP scores & Number of respondents & Minimum score & Maximum score & Mean score & SD \\
\hline Knowledge scores (out of 18) & 77 & 4 & 18 & 10.8 & 3.1 \\
\hline Attitudes scores (out of 41) & 77 & 0 & 35 & 25.9 & 6 \\
\hline Practice scores (out of 50 ) & 77 & 19 & 44 & 35.8 & 6 \\
\hline
\end{tabular}

KAP, knowledge, attitudes and practice; SD, standard deviation.

continuous data) for demographic and KAP data. To analyse the categorical variables, cross-tabulation was performed using the Fisher's exact test to determine whether there was an association between selected independent variables and KAP concerning the use and effects of UFH.

Application of the logistic regression model tested the strength of association between the independent variables and KAP variables, expressed as an odds ratio (OR). A $P$-value of $\leq 0.05$ at a $95 \%$ Confidence Interval (CI) denoted an association that was statistically significant.

As a preamble to the KAP results, the questionnaire response rate and respondents' demographic characteristics are presented.

\section{Results}

\section{Response rate}

All recruited dialysis centres participated in the study (Table 1): two tertiary government hospital dialysis centres $(28.6 \%)$ and five dialysis centres $(71.4 \%)$ from a private dialysis provider. Of the total population $(N=104)$ of renal unit practitioners who met inclusion criteria, 77 (74.0\%) participated in the study compared to the estimated sample size $(n=82,93.9 \%)$, therefore, no questionnaires were excluded from the final data analysis, even those with missing data. The highest proportion of missing data $(8.2 \%)$ was recorded for the knowledge section. There was a $70.0 \%$ response rate $(35 / 50)$ of practitioners from tertiary hospitals, and from the private sector, it was $77.8 \%(42 / 54)$.

\section{Demographic characteristics}

The majority of respondents $(94.8 \%, 73 / 77)$ were South African citizens (Table 2). There was a statistically significant association $(P=0.002, \mathrm{SD} \pm 10.8)$ between the variable professional category and age. A Scheffé post-hoc test showed that the difference in age between RNs and CTs reached statistical significance $(P<0.001,95 \%$ CI $7.56-19.41)$ and between ENs and CTs $(P=0.020,95 \%$ CI 1.70-24.24), but not between RNs and ENs. The association between gender and professional category reached statistical significance $(P<0.001)$. There was a statistically significant association $(P<0.001)$ between the variable professional category and qualification. Most respondents $(53.2 \%, 41 / 77)$ had $0-5$ years of experience (mean 9.4, $\mathrm{SD} \pm 9.3$ ), which did not reach statistical significance for the professional category. There was a statistically significant association $(P=0.001)$ between the variable professional category and having or not having in-service education on the pharmacological actions of UFH.

\section{Respondents' overall test scores for KAP}

Respondents' overall test scores achieved for KAP are presented in Table 3.

The mean score for knowledge was 10.8/18 (60.0\%); for attitude, 25.9/41 (63.2\%); and for practice, 35.8/50 (71.6\%).

\section{Knowledge}

Results for specific questions on respondents' knowledge of the use and effects of UFH are presented in Appendix 1 Table 1 - A1.

\section{Association between knowledge and selected independent variables}

The association between knowledge and selected independent variables is presented in Table 4.

The data in Table 4 shows that overall, $75.3 \%(58 / 77)$ of respondents had an acceptable level of knowledge regarding UFH, whilst $24.6 \%(19 / 77)$ had poor knowledge. Most of the RNs $(82.3 \%, 42 / 51)$ had an acceptable level of knowledge. The majority $(80.0 \%, 4 / 5)$ of ENs had poor knowledge of UFH, despite the fact that as employees within haemodialysis units, they administer UFH under supervision of RNs. There was a statistically significant association $(P=0.011)$ between the variable professional category and self-reported knowledge of UFH. Bivariate logistic regression analysis showed that the odds of the ENs having poor knowledge regarding UFH compared to the RNs were 18.7 times higher at a 95\% CI (1.9-187.4), and that this difference reached statistical significance $(P=0.013)$. The odds of the CTs having poorer knowledge than the RNs were 1.9 times higher, at a 95\% CI (0.6-6.1), but this difference did not reach statistical significance $(P=0.304)$.

The majority of respondents $41.5 \% \quad(32 / 77)$ who had an acceptable level of knowledge of UFH had $0-5$ years of experience. Ten of the 77 respondents (12.9\%) who had 11-35 years of experience displayed poor knowledge of UFH. There was no statistically significant association between the level of knowledge and the variables:

- years of experience $(P=0.604)$

- duration of orientation $(P=0.549)$

- in-service education $(P=0.101)$.

For in-service education on UFH, 1.3\% (1/77) of respondents were not included in the calculation. 
TABLE 4: Association between knowledge and selected independent variables.

\begin{tabular}{|c|c|c|c|}
\hline \multirow[t]{2}{*}{ Independent Variables } & \multicolumn{2}{|c|}{ Knowledge } & \multirow{2}{*}{$\begin{array}{l}\text { Fisher's exact } \\
\text { test } P \text {-value }\end{array}$} \\
\hline & $\begin{array}{c}\text { Acceptable } \\
\text { number (\%) }\end{array}$ & $\begin{array}{c}\text { Poor } \\
\text { number (\%) }\end{array}$ & \\
\hline \multicolumn{4}{|c|}{ Professional category ( $n=77$ ) } \\
\hline $\mathrm{RN}(n=51)$ & $42(72.4)$ & $9(47.4)$ & 0.011 \\
\hline $\mathrm{CT}(n=21)$ & $15(25.9)$ & $6(31.6)$ & \\
\hline $\mathrm{EN}(n=5)$ & $1(20.0)$ & $4(80.0)$ & \\
\hline \multicolumn{4}{|c|}{ Experience in years $(n=77 *)$} \\
\hline $0-5(n=41)$ & $32(55.2)$ & $9(47.4)$ & 0.604 \\
\hline $6-40(n=36)$ & $26(44.8)$ & $10(52.7)$ & \\
\hline \multicolumn{4}{|c|}{ Duration of orientation $(n=77)$} \\
\hline On orientation $(n=1)$ & $0(0.0)$ & $1(5.3)$ & 0.549 \\
\hline Days $(n=1)$ & $1(1.7)$ & $0(0.0)$ & \\
\hline Weeks $(n=25)$ & $20(34.5)$ & $5(26.3)$ & \\
\hline Months $(n=30)$ & $22(37.9)$ & $8(42.1)$ & \\
\hline Not applicable $(n=20)$ & $15(25.9)$ & $5(26.3)$ & \\
\hline \multicolumn{4}{|c|}{ In-service education of UFH ( $n=76)$} \\
\hline Yes $(n=29)$ & $19(32.8)$ & $10(55.6)$ & 0.101 \\
\hline No $(n=47)$ & $39(67.2)$ & $8(44.4)$ & \\
\hline
\end{tabular}

TABLE 5: Association between attitude and selected independent variables.

\begin{tabular}{|c|c|c|c|}
\hline \multirow[t]{2}{*}{ Independent Variables } & \multicolumn{2}{|c|}{ Attitude } & \multirow{2}{*}{$\begin{array}{l}\text { Fisher's exact } \\
\text { test } P \text {-value }\end{array}$} \\
\hline & $\begin{array}{c}\text { Positive } \\
\text { number (\%) }\end{array}$ & $\begin{array}{c}\text { Negative } \\
\text { number }(\%)\end{array}$ & \\
\hline \multicolumn{4}{|c|}{ Professional category ( $n=77$ ) } \\
\hline $\mathrm{RN}(n=51)$ & $38(69.1)$ & $13(59.1)$ & 0.637 \\
\hline $\mathrm{CT}(n=21)$ & $14(25.5)$ & $7(31.8)$ & \\
\hline $\mathrm{EN}(n=5)$ & $3(5.5)$ & $2(9.1)$ & \\
\hline \multicolumn{4}{|c|}{ Experience in years* $(n=77)$} \\
\hline $0-5(n=41)$ & $27(49.1)$ & $14(63.6)$ & 0.315 \\
\hline $6-40(n=36)$ & $28(50.9)$ & $8(36.4)$ & \\
\hline \multicolumn{4}{|c|}{ Duration of orientation $(n=77)$} \\
\hline On orientation $(n=1)$ & $0(0.0)$ & $1(4.5)$ & 0.119 \\
\hline Days $(n=1)$ & $0(0.0)$ & $1(4.5)$ & \\
\hline Weeks ( $n=25$ ) & $17(30.9)$ & $8(36.4)$ & \\
\hline Months $(n=30)$ & $21(38.2)$ & 9 (40.9) & \\
\hline Not Applicable $(n=20)$ & $17(30.9)$ & $3(13.6)$ & \\
\hline \multicolumn{4}{|c|}{ In-service education on UFH ( $n=76$ ) } \\
\hline Yes $(n=29)$ & $20(37.0)$ & $9(40.9)$ & 0.798 \\
\hline No $(n=47)$ & $34(63.0)$ & $13(59.1)$ & \\
\hline
\end{tabular}

\section{Attitude}

Data showed that the respondents' lack of knowledge concerning the use and administration of UFH was reflected in their attitude to its use and administration. Data in Table 5 shows the association between attitudes and selected independent variables.

Data in Table 5 show that most RNs $(74.5 \%$; 38/51), CTs $(66.6 \% ; 14 / 21)$ and ENs $(60.0 \% ; 3 / 5)$ had a positive attitude, but the association between professional category and attitude did not reach statistical significance. The association between years of experience and attitude and between inservice education on UFH and attitude was not statistically significant.
TABLE 6: Association between practice and selected independent variables.

\begin{tabular}{|c|c|c|c|}
\hline \multirow[t]{2}{*}{ Independent Variables } & \multicolumn{2}{|c|}{ Practice } & \multirow{2}{*}{$\begin{array}{c}\text { Fisher's } \\
\text { exact test } \\
P \text {-value }\end{array}$} \\
\hline & $\begin{array}{c}\text { Acceptable } \\
\text { number (\%) }\end{array}$ & $\begin{array}{l}\text { Unacceptable } \\
\text { number }(\%)\end{array}$ & \\
\hline \multicolumn{4}{|c|}{ Professional category $(n=77)$} \\
\hline $\mathrm{RN}(n=51)$ & $38(65.5)$ & $13(68.4)$ & 0.517 \\
\hline $\mathrm{CT}(n=21)$ & $15(25.9)$ & $6(31.6)$ & \\
\hline $\mathrm{EN}(n=5)$ & $5(8.6)$ & $0(0.0)$ & \\
\hline \multicolumn{4}{|c|}{ Experience in years $(n=77 *)$} \\
\hline $0-5(n=41)$ & $26(44.8)$ & $15(78.9)$ & 0.016 \\
\hline $6-40(n=36)$ & $32(55.2)$ & $4(21.1)$ & \\
\hline \multicolumn{4}{|c|}{ Duration of orientation $(n=77)$} \\
\hline On orientation $(n=1)$ & $0(0.0)$ & $1(5.3)$ & 0.601 \\
\hline Days $(n=1)$ & $1(1.7)$ & $0(0.0)$ & \\
\hline Weeks $(n=25)$ & $19(32.8)$ & $6(31.6)$ & \\
\hline Months $(n=30)$ & $23(39.7)$ & $7(36.8)$ & \\
\hline Not applicable $(n=20)$ & $15(25.9)$ & $5(26.3)$ & \\
\hline \multicolumn{4}{|c|}{ In-service education of UFH ( $n=76)$} \\
\hline Yes $(n=29)$ & $26(45.6)$ & $3(15.8)$ & 0.028 \\
\hline No $(n=47)$ & $31(54.4)$ & $16(84.2)$ & \\
\hline
\end{tabular}

\section{Practice}

Results for specific questions on respondents' practice regarding the use and effects of UFH are not presented in this article, but are available on request from the authors. Data in Table 6 show the association between practice and selected independent variables.

Across the different professional categories of renal unit practitioners, the results reveal that most had an acceptable level of self-reported competency regarding the use of UFH. The association between the independent variable professional category and the dependent variable practice was not statistically significant $(P=0.517)$.

Of the respondents with $0-5$ years' experience, most (63.4\%, $26 / 41$ ) reported an acceptable level of practice competency. The association between years of experience and selfreported practice concerning UFH was statistically significant $(P=0.016)$, therefore, bivariate logistic regression analysis was performed for strength of association between the two variables and for statistical significance, before making further judgements about the null hypothesis. Respondents who had $0-5$ years of experience were 4.6 times more likely to report having poor practice at a $95 \%$ CI (1.4-15.6), than respondents who had more than six years of experience, and this difference reached statistical significance $(P=0.014)$.

There was no statistically significant association between duration of orientation and self-reported good practice $(15 / 20,75.0 \%)$ in relation to UFH. The results of the Fisher's exact chi-squared test revealed that the association between in-service education and practice reached statistical significance $(P=0.028)$, and bivariate logistic regression analysis was performed. The odds of respondents who had no in-service education reporting poor practice were 4.3 times higher, at $95 \% \mathrm{CI}(1.1-16.5)$, than respondents who 
had education in pharmacological actions of UFH, and this difference reached statistical significance $(P=0.032)$.

The outcomes of the logistic regression tests confirm rejection of the null hypotheses that the variables professional category, years of experience and in-service education on the pharmacological actions of UFH do not influence renal unit practitioners' KAP. However, the null hypothesis, that the variable duration of orientation did not affect the renal unit practitioners' KAP, was accepted.

\section{Discussion}

Chronic haemodialysis treatment is the most common renal replacement therapy for patients diagnosed with Stage 5 adult ESKF. The patient is at risk of bleeding or clotting if the administered individualised dose of UFH is not appropriate. In the USA there is no standard heparin dose for patients on chronic haemodialysis and little is known about safety aspects of UFH in this context (Shen \& Winkelmayer 2012:473). However, international health organisations (NPSA 2006; ISMP 2006b; IHI 2008; Agency for Healthcare Research and Quality [AHRQ n.d.]) have appealed for safer practice to minimise avoidable complications experienced by patients receiving UFH.

The primary purpose of the study was achieved by describing renal practitioners' KAP regarding the use of UFH in selected adult chronic haemodialysis centres. Published medication KAP studies were located but not specific to UFH. Studies on nurses' knowledge of pharmacology conducted in the UK (Ndosi \& Newell 2008) and in Taiwan on nurses' knowledge of high-alert medication (Hsaio et al. 2010) recommend that, to be competent in medication administration, nurses should strive continuously to update their medication knowledge with supplementary pharmacology education programmes.

The secondary aim was achieved by establishing whether or not there was an association between selected independent variables and renal practitioners' KAP. The aims of the study were achieved by objectives.

\section{Outline of the results compared to the published literature}

Most respondents were in the middle adulthood age group (40-65 years) which, according to Erik Erikson's 1959 theory, is stage seven of psychosocial development, implying that if their needs are unfulfilled, they may experience 'stagnation' and feel 'unproductive' (McLeod 2008:3). In haemodialysis centres it is good practice (Community Tool Box 2013:2) for new staff to be assigned to a mentor for orientation before taking responsibility for patient care. Although this did occur, for most respondents the orientation did not include in-service education in UFH.

\section{Respondents' self-reported knowledge of UFH}

Results of a Malaysian KAP study on general medication amongst 40 medical nurses showed adequate knowledge (mean scores: knowledge 13.8, attitude 16.4 and practice 10.7), but a lack of in-depth knowledge of aspects of pharmacology (Raja, Daud \& Syed 2009:17). The mean score for nursing students' knowledge of pharmacology in 29 nursing schools was $55 \%$ and for medication calculation skills $66 \%$, but they performed poorly in knowledge retention and practical implementation in clinical areas (Dilles et al. 2011:499). In our study the majority of RNs and CTs had an acceptable level of knowledge of UFH but, overall, respondents reported incorrectly that UFH breaks down blood clots, whereas it prevents blood clots forming (Fischer 2007:178; Lankshear, Harden \& Simms 2010:49), as UFH is not a fibrinolytic agent. Most respondents did not know the correct antidote to or dosage for managing UFH overdose (1 mg of protamine sulphate to neutralise $100 \mathrm{IU}$ of UFH [European Best Practice Guidelines Expert Group on Haemodialysis 2002:65; Baglin et al. 2006:28; Lankshear et al. 2010:51; Lemon \& Crannage 2011:212]). Most respondents did not know the reason for not administering UFH orally (it is poorly absorbed). Most respondents did not know that the type of heparin used in their unit was a porcine derivative which carries a greater risk of anaphylaxis (Shen \& Winkelmayer 2012:475)

Some respondents' inability to calculate correct dosages of UFH was of deep concern, as this can have life-threatening consequences for patients. Nurses' medicating deficiencies were highlighted in a study conducted on medication knowledge, dose calculation (Barkhouse-Mackeen \& Murphy 2013:91) and medication errors which resulted from poor calculation skills (Polifroni, McNulty \& Allchin 2003:458; Wright 2007:279). A study on numerical skills and drug calculations in relation to patient safety, conducted in the UK in 2006 (McMullan, Jones \& Lea 2010:891) showed, that $55 \%(126 / 229)$ of nursing students and $45 \%(20 / 44)$ of RNs failed the numeracy test, and 92\% (211/229) of the students and $89 \%(39 / 44)$ of RNs failed the calculation test.

\section{Respondents' self-reported attitudes regarding the use and effects of UFH}

Respondents' lack of knowledge in certain areas was reflected in their attitude to the use and administration of UFH, but extrapolation to mean that poor knowledge translates to having poor attitudes must be interpreted with caution. Only a few respondents were greatly concerned that patients may experience adverse effects of UFH, implying a casual attitude regarding such a high-alert medication. More than half of the respondents felt uncomfortable administering UFH that had been prepared by others, and this attitude to practice is supported in the published literature (Chevalier et al. 2011:344).

The majority of respondents displayed a positive attitude in relation to the administration of UFH. Respondents with $0-5$ years of experience $(65.9 \% ; 27 / 41)$ presented the most positive attitude. 


\section{Respondents' self-reported practice regarding the use and effects of UFH}

The majority of all categories of renal practitioners reported having acceptable practice. The majority would always give the UFH dose prescribed by the nephrologist, and about half of them would contact the prescribing doctor if concerned about a patient's prescribed dose, whilst a few would adjust the dose and document the adjusted dose. Rather than first consulting the medicines formulary for UFH information, respondents would consult a doctor. Most respondents would always monitor patients for anaphylactic shock and few would never verify allergies with patients before administering UFH. The majority of respondents would always check the UFH dose with another person before administration, rather than only doing so sometimes. Most respondents would always document adverse effects of UFH and report related adverse effects in patients to unit managers. A study by Hanafi et al. (2012:21) in Tehran showed that $91 \%$ of nurses had never reported an adverse drug reaction (ADR) directly to the Iran Adverse Drug Reaction National Centre and 35\% were unaware of the centre's existence, but were most likely to report to doctors $(87.1 \%)$ and pharmacists $(1.8 \%)$. The reasons for not reporting ADR were:

- uncertainty of the adverse reactions (49.5\%)

- unawareness of reporting procedure (45.1\%)

- lack of time to complete a report (33\%) (Hanafi 2012:21).

However, Niccolai et al. (2004:148S) suggest that nonreporting directly to ADR databases could be attributed to nurses fearing reprisal and blame. A multinational systematic review of empirical evidence on the prevalence and nature of medication administration errors (Keers et al. 2013:1) showed that, despite improvement in medication safety, higher medication administration error (53.3\%) occurred via the intravenous route compared to other routes.

Study findings suggest that currently, in the seven research sites, there is not a set schedule for coagulation studies for patients on haemodialysis. Pittard (2001:75) and Winkler et al. (2007:499) support the need for strict laboratory monitoring of coagulation studies of patients, to establish a therapeutic dose to prevent under or over-anticoagulation. Respondents did not consider prolonged bleeding or clotting of patients' blood circuits (Pittard 2001:74) to be the adverse effects of UFH, which may account for them reportedly not having recently witnessed an adverse event. Respondents had not kept up to date with literature specifically on UFH, a concern echoed by Ndosi and Newel (2008:570) and Raja et al. (2009:17) that, in general, nurses lack in-depth knowledge of medication.

\section{Limitations of the study method}

Limiting the search strategy to published studies on renal unit practitioners' KAP regarding use and effects of UFH, limited the scope of the literature review. Had the search strategy included studies relating to KAP amongst health practitioners and to thromboprophylaxis more broadly, more studies might have been located. Structured individual interviews may have resulted in less missing data (total missing data $=169 / 3388$ [5.0\%]). Missing data should have been addressed during validation of the questionnaire and interpretation of the data.

The attitude section of the questionnaire was the most difficult to develop, as this is a subjective component, and it was measured using both Likert scale and closed-ended questions. Questions to elicit the respondents' attitude were based on the respondents' knowledge and practice regarding the use and effects of UFH, warranting cautious interpretation of responses. Post-hoc internal consistency of the questionnaire was performed, but this should have been before the experts validated the questionnaire.

There were problems with the pilot study sample size ( $n=3$ of an estimated $82,4 \%$ ) for testing the instrument reliability, as it fell short of an estimated pilot sample size of 10, recommended by Nieswiadomy (2002). Therefore, the validation results have to be interpreted with caution. Intraclass correlation (ICC) for testing reliability of the ratings for a typical, single rater (which does penalise systematic error) was not calculated, as there was only one rater within each group. The reliability testing of the instrument may have been strengthened, had Cohen's kappa or Fleiss kappa tests been performed, and also construct validity of the instrument.

The study did not achieve the estimated sample size of 82 (1.0\% margin of error, 95\% CI). Instead, 77/82 (93.9\%) respondents participated and this has implications for informing the implementation of the results. Professional category as an independent variable should not have been included as a measure against dependent variables $\mathrm{KAP}$, because of the unequal distribution of the different professional categories. In hindsight, perhaps the term dialysis personnel should have been used as an independent variable, without differentiating between the categories of professionals. Alternatively, the ENs could have been excluded as they do not have a specialist nephrology qualification.

The study would have been strengthened if a minimum acceptable knowledge score had been set, such as a more clinical criterion based on patient safety and what practitioners should know, benchmarked at the $75 \%$ quartile level.

\section{Strengths and evaluation of the study}

This study was evaluated using The Strengthening the Reporting of Observational Studies in Epidemiology (STROBE) (Vandenbroucke et al. 2007) checklist, to ensure that all the important aspects of a descriptive cross-sectional study were attended to. 


\section{Implications and recommendations for education}

The limited statutory scope of practice for ENs (South African Nursing Council, Republic of South Africa 1984) was reflected in their poor knowledge of UFH, and this has implications for their placement in haemodialysis units. Therefore, ENs should not practise independently in a haemodialysis unit, but at all times under the supervision of a registered nurse and not a clinical technologist. Pre and post-registration nursing education programmes should emphasise medication calculation, pharmacokinetics, pharmacotherapeutics and pharmacodynamic aspects of UFH. Nurses should be taught how to navigate medicine formularies and how to do literature searches to improve their medication knowledge to ensure life-long learning.

\section{Implications for practice and recommendations for clinical management teams}

Guidelines for safe administration of UFH and monitoring practices should be developed through consensus by an expert panel. Management teams should implement problem-based, in-service education programmes that include pharmacology, pharmacokinetics, pharmacodynamics, medication calculation and pharmacotherapeutics. Improving staff KAP regarding UFH should limit medical litigation and financial claims against individual health care personnel and institutions. Management teams should encourage renal unit practitioners to enrol for patient safety programmes such as the webinar by ISMP (2013:1), 'Improving Medication Safety through Staff Education and Competency Assessment: An Important Challenge for Healthcare Organisations'.

Management teams should establish pharmaco-vigilance units to encourage reporting of incidents and unsafe practice without naming, blaming and shaming, to augment the renal database of patients who experienced AEs associated with UFH. Staff could be provided with a bedside calibrated point-of-care testing apparatus to measure patients' activated partial thromboplastin time instead of having to wait for laboratory results.

Before new staff administer UFH, their competency level should be evaluated before and after the orientation programme and, if they do not pass the predetermined set score, remedial intervention should be instituted. Staff competency tests should be conducted annually and if results are poor, re-training and re-testing should be offered to ensure ongoing employment.

\section{Unanswered questions and recommendations for future research}

Shen and Winkelmayer (2012:483) suggest that large cluster randomised trials should be conducted in haemodialysis units to confirm the safe therapeutic range for different anticoagulants or pertaining to their risks and benefits. A renal nursing practice model should be developed for the local South African context for both the public and private chronic haemodialysis centres.

\section{Conclusion}

Results suggest that renal practitioners lack clinical guidelines for the safe use and monitoring of UFH. This has serious implications for patients receiving chronic haemodialysis and there are medico-legal consequences for individual health practitioners and their employers. Knowing that professional category influences knowledge and safe use of UFH, and that ENs had poor knowledge, their role in haemodialysis units needs urgent attention. Results suggest that there is a direct relationship between years of experience and quality of haemodialysis practice, and between having in-service education and quality of practice. Therefore, onduty rosters should take these factors into consideration to ensure optimal patient outcomes.

\section{Acknowledgements}

The authors thank Fresenius Medical Care for financially supporting this project and all the participating institutions and respondents. We are grateful to statisticians Dr M. Badri, K. Mauff and H. Carrera for assisting with data analysis.

\section{Competing interests}

The authors declare that they have no financial or personal relationship(s) that may have inappropriately influenced them in writing this article.

\section{Authors' contributions}

D.O. (University of Cape Town) did the conception and design, data collection, analysis and interpretation, writing of this article. U.K. (University of Cape Town) did the supervision, critical revision of this manuscript.

\section{References}

Agency for Healthcare Research and Quality, n.d., Guidelines on the use and monitoring of heparin, viewed 08 August 2011, from http://www.ahrq.gov/

Baglin, T., Barrowcliffe, T.W., Cohen, A., Greaves, M. \& The British Committee for Standards in Haematology, 2006, 'Guidelines on the use and monitoring of heparin', British Journal of Haematology 133, 19-34. http://dx.doi.org/10.1111/ j.1365-2141.2005.05953.x

Barkhouse-MacKeen, C.D. \& Murphy, A.L., 2013, 'Pharmacology in undergraduate nursing education: Innovative strategies for enhancing medication related knowledge, attitudes, skills and behaviours', Journal of Nursing Education and Practice 3(6), 91-101.

Bircher, A.J., Harr, T., Hohenstein, L. \& Tsakiris, D.A., 2006, 'Hypersensitivity reactions to anticoagulant drugs: Diagnosis and management options', Allergy 61, 1432-1440. http://dx.doi.org/10.1111/j.1398-9995.2006.01227.x

Bowling, A. \& Ebrahim, S. (eds.), 2007, Handbook of health research methods. Investigation, measurement and analysis, 1st edn., Open University Press, Berkshire, England

Brunet, P., Simon, N., Opris, A., Faure, V., Lorec, P.M., Portugal, H. et al., 2008, 'Pharmacodynamics of unfractionated heparin during and after a haemodialysis session', American Journal of Kidney Disease 51(5), 789-795. http://dx.doi. org/10.1053/j.ajkd.2007.12.040

Chevalier, B.A.M., Hudson, S., Thompson, K. \& Constantine, C., 2011, 'Patient outcomes, economic benefits associated with a heparin change in hemodialysis, and nurses' satisfaction', Nephrology Nursing Journal 38(4), 339-348.

Community Tool Box, 2013, viewed 15 November 2013, from http://ctb.ku.edu/en/ table-of-contents/structure/hiring-and-training/staff-orientation/main 
Davenport, A., 2009, 'Review article: Low-molecular-weight heparin as an alternative anticoagulant to unfractionated heparin for routine outpatient haemodialysis treatments', Nephrology 14, 455-461. http://dx.doi.org/10.1111/j.1440treatments', Nephro

Dilles, T., Vander Stichele, R.R., Van Bortel, L. \& Elseviers, M.M., 2011, 'Nursing students' pharmacological knowledge and calculation skills. Ready for practice?', Nurse Education Today 31(5), 499-505. http://dx.doi.org/10.1016/j. nedt.2010.08.009

Dorland, W.A.N., 2007, Dorland's illustrated medical dictionary, 31st edn., Saunders, Philadelphia, PA.

European Best Practice Guidelines Expert Group on Haemodialysis, European Renal Association, 2002, 'Section V: Chronic intermittent haemodialysis and prevention of clotting in the extracorpor[e]al system', Nephrology Dialysis Transplant 17(7) 63-71, viewed 04 October 2011, from http://www.ndt.oxfordjournals.org/ content/17/suppl 7/63.full.pdf+html

Fischer, K., 2007, 'Essentials of anticoagulation in haemodialysis', Haemodialysis International 11(2), 178-189. http://dx.doi.org/10.1111/j.1542-4758.2007. 00166.x

Furuhashi, M., Ura, N., Hasegawa, K., Yoshida, H., Tsuchihashi, K., Miura, T. et al., 2002 'Sonoclot coagulation analysis: New bedside monitoring for determination of the appropriate heparin dose during haemodialysis', Nephrology Dialysis Transplant 17(8), 1457-1462. http://dx.doi.org/10.1093/ndt/17.8.1457

Grissinger, M.C., Hicks, R.W., Kerock, M.A., Marella, W.M. \& Vaida, A., 2010, ‘Harmfu medication errors involving unfractionated and low-molecular-weight heparin in three patient safety reporting programs', Joint Commission Journal on Quality and Patient Safety 36, 195-202, viewed 22 January 2014, from http://psnet.ahrq.gov/ public/Grissinger-JCJQPS-2010-ID-18025.pdf

Hanafi, S., Torkamandi, H., Hayatshahi, A., Gholami, K. \& Javadi, M., 2012, 'Knowledge, attitudes and practice of nurse regarding adverse drug reaction reporting', Iran Journal of Nursing Midwifery Research (January-February) 17(1), 21-25.

Hsaio, G., Chen, I., Yu, S., Wei, I., Fang, Y. \& Tang, F., 2010, 'Nurses? Knowledge of highalert medications: Instrument development and validation', Journal of Advanced
Nursing 66(1), 177-190. http://dx.doi.org/10.1111/j.1365-2648.2009.05164.x

Institute for Healthcare Improvement, 2008, '5 Million lives campaign. Getting started kit: Preventing harm from high-alert medications', Cambridge MA, viewed 19 December 2011, from http://www.ihi.org/offerings/Initiatives/PastStrategiclnitiat ives/5MillionLivesCampaign/Pages/default.aspx

Institute for Safe Medication Practices, 2006a, viewed 19 December 2011, from https://www.ismp.org/tools/highalertmedication.pdf

Institute for Safe Medication Practices, 2006b, 'Our long journey towards a safetyminded just culture Part 1: Where we have been', viewed 19 December 2011, from http://www.ismp.org/newsletters/acutecare/archives/Sep06.asp

Institute for Safe Medication Practices, 2013, 'Improving medication safety through staff education and competency assessment: An important challenge for healthcare organisation', viewed 02 November 2013, from http://onlinestore. ismp.org/shop/item. aspx?itemid=208

Joint Commission on Accreditation of Healthcare Organisations, 2009, 'National patient safety goals', Oak Brook, IL, Joint Commission Resources, viewed 04 May 2013, from http://www.jointcommission.org/patientsafety/ nationalpatientsafetygoals

Keers, R.N., Williams, S.T., Cooke, J. \& Ashcroft, D.M., 2013, 'Prevalence and nature of medication administration errors in health care settings', The Annals of Pharmacotherapy 47(2), 237-256, viewed 04 May 2013, from http://www. medscape.com

Lankshear, A., Harden, J. \& Simms, J., 2010, 'Safe practice for patients receiving anticoagulant therapy', Nursing Standard 24(20), 47-55. http://dx.doi org/10.7748/ns2010.01.24.20.47.c8157

Lemon, S.J. \& Crannage, A.J., 2011, 'Pharmacologic anticoagulation reversal in the emergency department', Advanced Emergency Nursing Journal 33(3), 212-223. DOI:109/TME.Ob013e31822638ae.

Marx, R.G., Menezes, A., Horovitz, L., Jones, E.C. \& Warren, R.F., 2003, 'A comparison of two time intervals for test -Retest reliability of health status instruments', Journa of Clinical Epidemiology August 56(8), 730-735. http://dx.doi.org/10.1016/ S0895-4356(03)00084-2

McLeod, S.A., 2008, 'Erik Erikson|Psychosocial stages - Simply psychology', viewed 20 August 2013, from http://www.simplypsychology.org/Erik-Erikson.html

McMullan, M., Jones, R. \& Lea, S., 2010, 'Patient safety: Numerical skills and drug calculation abilities of nursing students and registered nurses', Journal of Advanced Nursing 66(4), 891-899. http://dx.doi.org/10.1111/j.1365-2648.2010.05258.x
National Patient Safety Agency, 2006, 'Risk assessment of anticoagulation therapy executive summary', viewed 20 March 2011, from http://www.npsa.nhs.uk/ health/alerts

Ndosi, M.E. \& Newell, R., 2008, 'Nurses' knowledge of pharmacology behind drugs they commonly administer', Journal of Clinical Nursing 18, 570-580. http://dx.doi. org/10.1111/j.1365-2702.2008.02290.x

Niccolai, C.S., Hicks, R.W., Oertel, L., Francis, J.L. \& Heparin Consensus Group, 2004, 'Unfractionated heparin: Focus on a high alert drug', Pharmacotherapy 24(8), 146S-155S. http://dx.doi.org/10.1592/phco.24.12.146S.36107

Nieswiadomy, R.M., 2002, Foundations of nursing research, 4th edn., Pearson Education, Upper Saddle River, NJ.

Ouseph, R. \& Ward, R.A., 2000, 'Anticoagulation for intermittent haemodialysis', Seminars in Dialysis 13(3), 181-187. http://dx.doi.org/10.1046/j.1525139X.2000.00052.x

Palmer, S.C., Palmer, A.R., Craig, J.C., Johnson, D.W., Stroumza, P., Frantzen, L., Leal, M., Hoischen, S., Hegbrant, J. \& Strippoli, G.F.M., 2014, 'Home versus in-centre
haemodialysis for end-stage kidney disease', Cochrane Database of Systematic Reviews haemodialysis for end-stage kidney disease', Cochrane Database of Systematic Reviews

Pittard, J.D., 2001, 'Heparin therapy in routine hemodialysis', Nephrology News \& Issues April 15(5), 73-75, viewed 18 June 2011, from http://www.nephronline. com

Polifroni, E.C., McNulty, J. \& Allchin, L., 2003, 'Medication errors: More basic than a system issue', Journal of Nursing Education 42(10), 455-458.

Raja, L.R.G., Daud, F. \& Syed, Z.S.Z., 2009, 'Knowledge, attitude and practice of nurses in administering oral medication at medical ward, University Kebangsaan Malaysia Medical Centre', Journal of Medicine \& Health 4(1), 16-24.

Rousson, V., Gassser, T. \& Seifert, B., 2002, 'Assessing intrarater, interrater and testretest reliability of continuous measurement', Statistica in Medicine 21, 34313446. http://dx.doi.org/10.1002/sim.1253

Roy, A. \& Kalra, V., 2012, 'Anticoagulation in haemodialysis', JIMSA April-June 25(2), 107-109.

Schilling, L.S., Dixon, J.K., Knafl, K.A., Grey, M., Ives, B. \& Lynn, M.R., 2007, 'Determining content validity of a self-report instrument for adolescents using a heterogeneous expert panel', Nursing Research 56(5), 361-366. http://dx.doi.org/10.1097/01. NNR.0000289505.30037.91

Shen, J.I. \& Winkelmayer, W.C., 2012, 'Use and safety of unfractionated heparin for anticoagulation during maintenance hemodialysis', American Journal of Kidney Diseases 60(3), 473-486. http://dx.doi.org/10.1053/j.ajkd.2012.03.017

South African Nursing Council, Republic of South Africa, 1984, 'SANC regulations 2598 of 1984 as amended', viewed 20 March 2011, from http://www.sanc.co.za

South African Nursing Council, Republic of South Africa, 2005, Nursing Act No. 33 of 2005, viewed 20 March 2011, from http://www.sanc.co.za/pdf/Nursing\%20 act $\% 202005$.PDF

South African Qualifications Authority, 2014, 'Bachelor: Clinical Technology', SAQA Qualification Identity 64698, viewed 09 December 2014, from http://www. hpcsa.co.za/Uploads/editor/UserFiles/downloads/rct/reg_qual_bach_clin tech_20_02_2013.pdf

South African Renal Society Guidelines, 2006, 'Guidelines for optimal care of patients on chronic dialysis in South Africa', viewed 30 January 2014, from http://www. sa-renalsociety.org/guidelines.asp

Suranyi, M. \& Chow, J.S., 2010, 'Review: Anticoagulation for haemodialysis', Nephrology 15(4), 386-392. http://dx.doi.org/10.1111/j.1440-1797.2010.01298.x

Vandenbroucke, J.P., von Elm, E., Altman, D.G., Gotzsche, P.C., Mulrow, C.D., Pocock, S.J., Poole, C., Schlesselman, J.J. et al., 2007, 'Strengthening the reporting of observational studies in epidemiology (STROBE). Explanation and elaboration' Epidemiology 18(6), 805-835. http://dx.doi.org/10.1097/EDE.0b013e3181577511

Winkler, A.M., Sheppard, C. \& Fantz, C., 2007, 'Laboratory monitoring of heparin Challenges and opportunities', Laboratory Medicine 38(8), 499-502, viewed 14 March 2014, from http://www.labmedicine.com

World Health Organisation, 2005, 'Adverse events', viewed 02 February 2014, from http://www.who.int/patientsafety/information_centre/Living_less_dangerously. pdf-313k

World Medical Association, 2008, 'Declaration of Helsinki', viewed 27 June 2012, from http://www.wma.net/en/publications/10policies/b3/pdf

Wright, K., 2007, 'Student nurses need more than maths to improve their drug calculating skills', Nurse Education Today 27(4), 278-285. http://dx.doi. org/10.1016/j.nedt.2006.05.007 


\section{Appendix 1}

TABLE 1-A1: Respondents' self-reported knowledge results by professional category.

\begin{tabular}{|c|c|c|c|}
\hline \multirow[t]{2}{*}{ Questions and responses } & \multicolumn{3}{|c|}{ Professional category $(n=77)$} \\
\hline & RN $(n=51)$ Number $(\%)$ & CT $(n=21)$ Number $(\%)$ & EN $(n=5)$ Number $(\%)$ \\
\hline \multicolumn{4}{|c|}{ Q010. Query bleeding tendencies before UFH is administered } \\
\hline Yes & $51(100.0)$ & $19(90.5)$ & $5(100.0)$ \\
\hline No & $0(0.0)$ & $1(4.8)$ & $0(0.0)$ \\
\hline Missing & $0(0.0)$ & $1(4.8)$ & $0(0.0)$ \\
\hline Total & $51(100.0)$ & $21(100.0)$ & $5(100.0)$ \\
\hline \multicolumn{4}{|l|}{ Q011. UFH breaks down blood clots? } \\
\hline Yes & $25(49.0)$ & $4(19.0)$ & $1(20.0)$ \\
\hline No & $25(49.0)$ & $16(76.2)$ & $3(60.0)$ \\
\hline Unsure & $0(0.0)$ & $1(4.8)$ & $1(20.0)$ \\
\hline Missing & $1(2.0)$ & $0(0.0)$ & $0(0.0)$ \\
\hline Total & $51(100.0)$ & $21(100.0)$ & $5(100.0)$ \\
\hline \multicolumn{4}{|c|}{ Q012. Effects of administering UFH with low aPTT } \\
\hline Bleeding & $22(43.1)$ & $11(52.4)$ & $3(60.0)$ \\
\hline Nil ill effects & $12(23.5)$ & $1(4.8)$ & $0(0.0)$ \\
\hline Bleeding and unscheduled hospitalisation & $16(31.4)$ & $8(38.1)$ & $0(0.0)$ \\
\hline Missing & $1(2.0)$ & $1(4.8)$ & $2(40.0)$ \\
\hline Total & $51(100.0)$ & $21(100.0)$ & $5(100.0)$ \\
\hline \multicolumn{4}{|c|}{ Q013. Blood pressure reading of $240 / 140 \mathrm{mmHg}$. Administer UFH or not } \\
\hline Yes & $5(9.8)$ & $1(4.8)$ & $1(20.0)$ \\
\hline No & $42(82.4)$ & $17(81.0)$ & $3(60.0)$ \\
\hline Unsure & $4(7.8)$ & $1(4.8)$ & $0(0.0)$ \\
\hline Missing & $0(0.0)$ & $2(9.5)$ & $1(20.0)$ \\
\hline Total & $51(100.0)$ & $21(100.0)$ & $5(100.0)$ \\
\hline \multicolumn{4}{|c|}{ Q014. UFH not administered following platelet count } \\
\hline $420-450 \times 10^{9 / 1}$ & $4(7.8)$ & $0(0.0)$ & $0(0.0)$ \\
\hline $50-80 \times 10^{9 / 1}$ & $41(80.4)$ & $15(71.4)$ & $4(80.0)$ \\
\hline $150-180 \times 10^{9 / 1}$ & $4(7.8)$ & $3(14.3)$ & $0(0.0)$ \\
\hline Missing & $2(3.9)$ & $3(14.3)$ & $1(20.0)$ \\
\hline Total & $51(100.0)$ & $21(100.0)$ & $5(100.0)$ \\
\hline \multicolumn{4}{|c|}{ Q015. Method to arrest bleeding post-haemodialysis session to counteract effects of UFH } \\
\hline PS 1 mg/ 100 IU UFH & $23(45.1)$ & $5(23.8)$ & $1(20.0)$ \\
\hline PS 2 mg/1000 IU UFH & $10(19.6)$ & $8(38.1)$ & $3(60.0)$ \\
\hline Vitamin K 1 mg & $9(17.6)$ & $1(4.8)$ & $0(0.0)$ \\
\hline Unsure & $9(17.6)$ & $6(28.6)$ & $0(0.0)$ \\
\hline Missing & $0(0.0)$ & $1(4.8)$ & $1(20.0)$ \\
\hline Total & $51(100.0)$ & $21(100.0)$ & $5(100.0)$ \\
\hline \multicolumn{4}{|l|}{ Q016. Reason UFH not administered orally } \\
\hline Effectiveness & $4(7.8)$ & $0(0.0)$ & $0(0.0)$ \\
\hline Effects & $23(45.1)$ & $9(42.9)$ & $2(40.0)$ \\
\hline Pharmacokinetics & $9(17.6)$ & $1(4.8)$ & $0(0.0)$ \\
\hline Destroyed by stomach acids & $10(19.6)$ & $8(38.1)$ & $0(0.0)$ \\
\hline Unsure & $1(2.0)$ & $1(4.8)$ & $0(0.0)$ \\
\hline Missing & $4(7.8)$ & $2(9.5)$ & $3(60.0)$ \\
\hline Total & $51(100.0)$ & $21(100.0)$ & $5(100.0)$ \\
\hline \multicolumn{4}{|c|}{ Q017. Importance of having the patient's baseline urea values before administering the first dose of UFH } \\
\hline Bleeding risk & $31(60.8)$ & $12(57.1)$ & $1(20.0)$ \\
\hline Increased urea levels & $1(2.0)$ & $0(0.0)$ & $1(20.0)$ \\
\hline Risk of complications & $4(7.8)$ & $3(14.3)$ & $0(0.0)$ \\
\hline Unsure & $4(7.8)$ & $1(4.8)$ & $0(0.0)$ \\
\hline Dosage & $1(2.0)$ & $0(0.0)$ & $0(0.0)$ \\
\hline Information & $1(2.0)$ & $0(0.0)$ & $0 .(0.0)$ \\
\hline Missing & $9(17.6)$ & $5(23.8)$ & $3(60.0)$ \\
\hline Total & $51(100.0)$ & $21(100.0)$ & $5(100.0)$ \\
\hline \multicolumn{4}{|l|}{ Q018. Route of administration of UFH } \\
\hline Intravenously & $37(72.5)$ & $11(52.3)$ & $5(100.0)$ \\
\hline Via dialysis machine & $13(25.5)$ & $7(33.3)$ & $3(60.0)$ \\
\hline Bolus dosage & $1(2.0)$ & $2(9.5)$ & $0(0.0)$ \\
\hline Missing & $0(0.0)$ & $1(4.8)$ & $0(0.0)$ \\
\hline Total & $51(100.0)$ & $21(100.0)$ & $2(40.0)$ \\
\hline
\end{tabular}


TABLE 1-A1 (Continues...): Respondents' self-reported knowledge results by professional category.

\begin{tabular}{|c|c|c|c|}
\hline \multirow[t]{2}{*}{ Questions and responses } & \multicolumn{3}{|c|}{ Professional category $(n=77)$} \\
\hline & RN $(n=51)$ Number $(\%)$ & CT $(n=21)$ Number $(\%)$ & EN $(n=5)$ Number $(\%)$ \\
\hline \multicolumn{4}{|l|}{ Q019. Type of UFH used } \\
\hline Porcine & $20(39.2)$ & $7(33.3)$ & $1(20.0)$ \\
\hline Bovine & $10(19.6)$ & $6(28.6)$ & $0(0.0)$ \\
\hline Other & $10(19.6)$ & $0(0.0)$ & $2(40.0)$ \\
\hline Unsure & $8(15.7)$ & $6(28.6)$ & $0(0.0)$ \\
\hline Missing & $3(5.9)$ & $2(9.5)$ & $2(40.0)$ \\
\hline Total & $51(100.0)$ & $21(100.0)$ & $5(100.0)$ \\
\hline \multicolumn{4}{|l|}{ Q020. UFH temperature storage } \\
\hline Patient temp & $1(2.0)$ & $0(0.0)$ & $0(0.0)$ \\
\hline$<25$ degrees $C$ & $32(62.7)$ & $18(85.7)$ & $2(40.0)$ \\
\hline$>25$ degrees $\mathrm{C}$ & $6(11.8)$ & $1(4.8)$ & $0(0.0)$ \\
\hline Room temp & $6(11.8)$ & $1(4.8)$ & $2(40.0)$ \\
\hline Missing & $6(11.8)$ & $1(4.8)$ & $1(20.0)$ \\
\hline \multicolumn{4}{|c|}{ Q021. A patient needs to receive $2000 \mathrm{IU}$ in stock $20000 \mathrm{IU}$ of UFH. Calculate the dose of UFH } \\
\hline Hyperkalemia & $22(43.1)$ & $8(38.1)$ & $2(40.0)$ \\
\hline Nil & $9(17.6)$ & $1(4.8)$ & $2(40.0)$ \\
\hline Don't know & $8(15.7)$ & $5(23.8)$ & $0(0.0)$ \\
\hline Inhibit the secretion of aldosterone-hyperkalemia & $3(5.9)$ & $2(9.5)$ & $0(0.0)$ \\
\hline Missing & $9(17.6)$ & $5(23.8)$ & $1(20.0)$ \\
\hline Total & $51(100.0)$ & $21(100.0)$ & $5(100.0)$ \\
\hline \multicolumn{4}{|c|}{ Q22. A patient needs to receive $2000 \mathrm{IU}$ in stock $20000 \mathrm{IU}$ of UFH. Calculate the dose of UFH } \\
\hline $10 \mathrm{~mL}$ & $32(62.7)$ & $15(71.4)$ & $0(0.0)$ \\
\hline $2000 \mathrm{IU}$ & $0(0.0)$ & $2(9.5)$ & $0(0.0)$ \\
\hline 10 ML- 100 IU & $0(0.0)$ & $1(4.8)$ & $0(0.0)$ \\
\hline $01-5 \mathrm{~mL}$ & $5(9.8)$ & $0(0.0)$ & $0(0.0)$ \\
\hline $10-100$ & $5(9.8)$ & $0(0.0)$ & $1(20.0)$ \\
\hline 1000 IU & $3(5.9)$ & $0(0.0)$ & $0(0.0)$ \\
\hline Missing & $3(5.9)$ & $3(14.3)$ & $3(60.0)$ \\
\hline Total & $51(100.0)$ & $21(100.0)$ & $5(100.0)$ \\
\hline
\end{tabular}

